\title{
The Volatility of ASIAN Stock Exchange Post Monetary Crisis: Utilizing ARCH Family Model
}

\author{
Ahmad Juliana $^{1}$, Roni Padliansyah ${ }^{2}$, Riska Yulianti ${ }^{3}$, Nurul Hidayat ${ }^{4}$ \\ Program Studi Manajemen - Univeristas Borneo Tarakan ${ }^{1,3,4}$ \\ Jurusan Akuntansi - Univeristas Borneo Tarakan ${ }^{2}$ \\ \{ahmadjuliana75@gmail.com¹, ronipadliansyah,@gmail.com², \\ yulianti.riska15@gmail.com ${ }^{3}$, nurul.hidayat8910@gmail.com ${ }^{4}$ \}
}

\begin{abstract}
This study examines heteroscedasticity in the index data of 5 countries, including Malaysia, China, Indonesia, Singapore and Japan. The study also determines the level of volatility that can describe future returns and risks that affect investment behavior. Additionally, this research analyzes whether post-crisis economic growth can affect a countries volatility level. The ARCH model will describe volatility in 5 indexes, while the Symmetric and Asymmetric GARCH methods capture negative shocks affecting the level of volatility. The results showed significant ARCH and GARCH effects, such that market fluctuations or the level of volatility that occurs after a crisis is quite large and shocks have an influence. However, the GARCH-M model (1.1) for the four sample countries did not establish any significant risk premium. Different events cause significant risk premiums are in Singapore. Asymmetric modeling in both EGARCH (1.1) and TGARCH (1.1) models showed insignificant results in all 5 sample countries. This implies that negative shocks do not affect investors' responses than positive ones, which influences the market's volatility level. The study modeled volatility in 4 Asian countries and Indonesia using the ARCH family approach to increase the robustness of capturing ASIAN stock exchanges' uncertainty.
\end{abstract}

Keyword: Volatility; ARCH Model; Symmetric GARCH; Asymmetric GARCH

\section{Introduction}

The capital market is where fund seekers and over-funders meet boosting economic growth in a country. Bargaining forms of volatility that describes the negative and positive sides of the capital market. The negative side has a high risk, especially when the level of volatility is high. In comparison, the positive side allows investors to have a profit higher than the level of volatility. Also, the economic situation of a country contributes to the capital market's movement, reflecting the volatility state. Developed and developing countries, such as Japan, Singapore, China, Malaysia and Indonesia, were impacted by the 2007-2008 monetary crisis. The main topic in this research is how fluctuating economic growth in Indonesia is led by two different presidencies described by the movement of the Jakarta Stock Exchange stock index.

This study determines the level of volatility that can describe future returns and risks that 
affect investment behavior. Additionally, the study examines whether post-crisis economic growth can affect the volatility of several Asian countries such as Japan, Singapore, China, Malaysia and Indonesia.

\section{Literature Review}

According to Vidanage, et al. [1], the reasons and importance of predicting volatility include influencing financial, investment, hedging, asset diversification decisions. Akhtar and Khan [2] stated that volatility increases profits and causes doubts among investors since it presents risks and causes market inefficiencies. Therefore, high volatility increases risks in the Indonesian capital market, which causes losses in future returns. Sharma [3] stated that the forecast of financial assets volatility has important implications on pricing, portfolio selection, risk management and trading strategies. According to Çelik and Ergin [4], volatility plays a vital role in finance's theoretical and practical applications. The availability of high-frequency data brings a new dimension to volatility modeling and estimated financial asset returns. Lim and Sek [5] stated that volatility in the Malaysian stock market caused variations in returns and higher risks. Therefore, volatility returns could be the total profits or losses from investments over a certain period.

\subsection{Descriptive Statistics}

Balnaves and Caputi [6] stated that descriptive statistics analyzes collected data without making an accepted or generalized conclusion. According to Howell [7], descriptive studies are used as the basis for decision-making and predicting the results of business strategies after recognizing data patterns and distribution behavior.

\subsection{Unit Root Test (Augmented Dickey-Fuller Test)}

Stationary data is obtained when the data average fluctuates and the variance is constant. The Unit Root Test (ADF Test) is one way to measure stationarity in averaged data. Ariefianto [8] stated that testing the unit root of Dickey and Fuller [9] was conducted by calculating the statistical value (statistic $t$ ) of the coefficient $\gamma$ and comparing the results with the critical value. Kuhe, et al. [10] used the ADF test with de-trending to optimize the unit root results based on the following hypothesis.

$\mathrm{H}_{0}=$ data not stationary where $P$-value $>\alpha$ (Series contains Unit Root)

$\mathrm{H}_{1}=$ stationary data where $P$-value $<\alpha$ (Stationary Series)

\subsection{Heteroscedasticity Test}

Ariefianto [8] stated that the residual variance is constant in the Markov Gauss assumption and is not influenced by changes in free variables. When this assumption is fulfilled, the residual is homoskedasticity, while the opposite is heteroscedasticity. Heteroscedasticity causes a standard error, which influences bias in the regression model. Consequently, the variance-covariance matrix used to calculate the standard error parameter becomes biased with the hypothesis and a significance level of 0.05 , as shown below.

$\mathrm{H}_{0}=$ No Heteroscedasticity effect

$\mathrm{H}_{1}=$ Heteroscedasticity effect 


\section{Methodology}

\subsection{Formation of the Model}

The model formation was chosen based on the results of previous studies where the ARCH (1), GARCH $(1,1)$, GARCH-M $(1,1)$, E-GARCH $(1,1)$, TGARCH $(1,1)$ approaches were sufficient to describe volatility based on the value of Akaike Info Criterion (AIC) and Log-Likelihood (LL) Akhtar and Khan [2]

\subsection{Symmetrical Model}

\section{a) $\mathrm{ARCH}$}

ARCH means estimation with a conditional variance model, where the residual variant at a one-time point is a function at another. The ARCH was modeled by Ariefianto [8], as shown below.

$\sigma^{2} t=\operatorname{var}\left(u_{t} \mid u_{t-1}, u_{t-2} \ldots\right)=E\left(u_{t} \mid u_{t-1}, u_{t-2} \ldots\right)$

\section{b) GARCH}

The conditional variants in this model are not influenced by past residual alternatives but are affected by lag. Abdalla and Suliman [11] showed the GARCH model in a mathematical formula, as illustrated below.

$\sigma_{\mathrm{t}}^{2}=\omega+\sum_{j=1}^{q} \mathrm{a}_{\mathrm{j}} \varepsilon_{\mathrm{t}-1}^{2}+\sum_{i=1}^{\mathrm{p}} \beta_{\mathrm{i}} \sigma^{2}{ }_{\mathrm{t}-1}$

\section{c) GARCH-M}

GARCH-M is a description of GARCH, which allows for the conditional mean of a sequence depending on the standard deviation or conditional variance [11]. Huang, et al. [12] and Ariefianto [8] developed the mathematical formula of GARCH-M, as shown below.

$\mathrm{y}_{\mathrm{t}}=\mu+\delta \sigma_{\mathrm{t}-1}+u_{\mathrm{t}} ; u_{\mathrm{t}}$

$\sigma_{\mathrm{t}}^{2}=\alpha_{0}+\alpha_{1} u_{\mathrm{t}-1}^{2}+\alpha_{2} \sigma_{\mathrm{t}-1}^{2}$

\subsection{Asymmetrical Model}

\section{a) EGARCH}

SHAMIRI, et al. [13] stated that E-GARCH counters the weaknesses of standard GARCH in terms of leverage effects and parameter limits. The model used in Ariefianto [8] is written, as shown below.

$\operatorname{In}\left(\sigma_{\mathrm{t}}^{2}\right)=\omega+\beta \operatorname{In}\left(\sigma_{\mathrm{t}-1}^{2}\right)+\gamma \frac{u}{\sqrt{\sigma 2} t-1}^{\mathrm{t}-1}+\alpha\left[\frac{|u t-1|}{\sqrt{\sigma 2 t-1}}-\sqrt{\frac{2}{\pi}}\right]$ 


\section{b) TGARCH}

T-GARCH is a volatility model that can be used to read leverage effects [11]. Ariefianto [8] showed the mathematical formula of the T-GARCH model, as written below.

$\sigma_{\mathrm{t}}^{2}=\alpha_{0}+\alpha_{1} u_{t-1}^{2}+\beta \sigma_{\mathrm{t}-1}^{2}+\gamma u_{\mathrm{t}-1}^{2} I_{\mathrm{t}-1}$

\subsection{Population and Sample}

This study's population was the ASIA country index in the capital market within 10 years. Purposive sampling was used in several steps, including the selection of developed and developing Asian such as Singapore and Japan, China, Malaysia and Indonesia. Secondly, this method identified 10 years from the post-crisis economic growth from January 5th, 2009 to December 27th, 2019. The total sample size was 2266 daily data of stock indexes from 5 working days in 5 sample countries, including KLSE, SSEC, JKSE, STI and Nikkei 225.

\subsection{Conceptual Framework or Method of Analysis}

Index data was processed and analyzed using Descriptive Statistics, Unit Root with ADF, and Heteroskedasticity tests. The index data was examined using S1ymmetric models (ARCH, GARCH, GARCH-M) and Asymmetric Models (E-GARCH, P-GARCH, T-GARCH). Translations were made from modeling results implications to draw conclusions.

\section{Results and Discussion}

Table 1. Descriptive Statistics

\begin{tabular}{|c|c|c|c|c|c|}
\hline & KLSE & SSEC & JKSE & STI & NIKKEI \\
\hline The mean & 1608,848 & 2795,787 & 4589,372 & 3041,189 & 15226.16 \\
\hline Median & 1658,910 & 2857,180 & 4768,280 & 3116,640 & 15376.24 \\
\hline Maximum & 1895,180 & 5166,350 & 6680,620 & 3609,240 & 24124.15 \\
\hline Minimum & 838,300 & 1863,370 & 1256,110 & 1485,750 & 7054,980 \\
\hline Std. Dev & 219.4115 & 525.0677 & 1273,270 & 341.1441 & 5057,685 \\
\hline Skewness & -1.438002 & 0.725027 & -0.584969 & -1.834634 & 0.061656 \\
\hline Kurtosis & 4.924167 & 4,560562 & 2.752428 & 7.966142 & 1.528647 \\
\hline Jarque-Bera & 1130,028 & 428.2748 & 134.9607 & 3598,150 & 205.7455 \\
\hline Sum & 3644041 . & 6332457. & 10394928 & 6888293 & 34487261 \\
\hline Observations & 2265 & 2265 & 2265 & 2265 & 2265 \\
\hline
\end{tabular}

Source: processed with Eviews10 application

Indonesia's JKSE index had a mean, median and standard deviation value of 4,589.37, $4,768.28$ and 1273.27 , respectively. The skewness value was -0.58 , which shows that the graph's average data distribution leaned towards the right with a value. Also, kurtosis's value was $2.75<3$, which means the distribution curve was platykurtic and the market shock was not too high.

\subsection{Stationary Test}

The Stationarity ADF Test model results showed that the index data was stationary at some 
level such that the KLSE index from Malaysia was $0.01<0.05$ and the STI value of Singapore was $0.01<0.05$. However, the ADF test was carried out at the first different level so that the data could be stationary in all 5 countries. The SSEC index in China had a probability value of $0.0001<0.05$, while the JKSE index in Indonesia had a probability of $0.0000<0.05$. Furthermore, the Nikkei 225 index in Japan had a probability value of $0.001<0.05$.

\subsection{Heteroscedasticity Test}

Table 2. Heteroscedasticity Test

\begin{tabular}{ccccc}
\hline Index & F-statistics & TR $^{\mathbf{2}}$ & Prob. $^{*}(5)$ & $\boldsymbol{\alpha}$ \\
\hline KLSE & 554379.2 & 2258.39 & 0.00 & 0.05 \\
SSEC & 40850.73 & 2202,087 & 0.00 & 0.05 \\
JKSE & 651094.4 & 2259,079 & 0.00 & 0.05 \\
STI & 166610.5 & 2247,775 & 0.00 & 0.05 \\
Nikkei & 195652.0 & 2250.005 & 0.00 & 0.05 \\
\hline
\end{tabular}

Source: Processed with the Eviews 10 application

Table 2 shows that each index experienced heteroscedasticity because results scored a sequential value of probability $<0.05$. Akhtar and Khan [2] stated that heteroscedasticity in the model makes it possible to apply the GARCH.

Symmetrical \& Asymmetrical Model.

Table 3. Symmetrical and Asymmetrical

\begin{tabular}{|c|c|c|c|c|c|c|}
\hline & & $\operatorname{ARCH}(1)$ & $\begin{array}{c}\text { GARCH } \\
(1,1)\end{array}$ & $\begin{array}{c}\text { GARCH-M } \\
(1,1)\end{array}$ & $\begin{array}{c}\text { EGARCH } \\
(1,1)\end{array}$ & $\begin{array}{c}\text { TGARCH } \\
(1,1)\end{array}$ \\
\hline \multirow[t]{5}{*}{$\omega$} & KLSE & 1664,972 & 1692,069 & 3.568697 & -0.671133 & 1691,569 \\
\hline & SSEC & 2931,858 & 2928,724 & 7.616388 & -0.160207 & 2928,691 \\
\hline & JKSE & 4868,609 & 4868,564 & 1.218186 & -0.697105 & 4868,585 \\
\hline & STI & 3199,833 & 3200,119 & 43.99613 & -0.138616 & 3200,042 \\
\hline & Nikkei & 15354.43 & 15987.49 & -10.9356 & -0.372446 & 15327.64 \\
\hline \multirow[t]{5}{*}{$\alpha$} & KLSE & 0.98278 & 1.041204 & 0.024782 & 1.159291 & 0.906626 \\
\hline & SSEC & 0.986498 & 1.049776 & 0.066421 & 1.435279 & 1.071408 \\
\hline & JKSE & 0.997074 & 0.831879 & 0.00609 & 1.55021 & 0.84078 \\
\hline & STI & 0.9975 & 1.019643 & 0.01639 & 1.429443 & 1.003792 \\
\hline & Nikkei & 0.994494 & 1.33425 & 0.043411 & 1.578638 & 0.981108 \\
\hline \multirow[t]{5}{*}{$\beta$} & KLSE & & -0.457103 & 0.889835 & 0.95063 & -0.584529 \\
\hline & SSEC & & -0.039097 & 0.943146 & 0.893877 & -0.159014 \\
\hline & JKSE & & 0.175587 & 0.867633 & 0.937764 & 0.174951 \\
\hline & STI & & -0.02257 & 0.931071 & 0.878238 & -0.023234 \\
\hline & Nikkei & & -0.911401 & 0.852025 & 0.928092 & 0.043787 \\
\hline \multirow[t]{5}{*}{$\lambda$} & KLSE & & & 0.092536 & & \\
\hline & SSEC & & & -0.021879 & & \\
\hline & JKSE & & & 0.068821 & & \\
\hline & STI & & & -0.24376 & & \\
\hline & Nikkei & & & -0.024696 & & \\
\hline \multirow[t]{5}{*}{$\gamma$} & KLSE & & & & $-0,010365$ & 0.459122 \\
\hline & SSEC & & & & -0.017537 & 0.031058 \\
\hline & JKSE & & & & 0.001008 & -0.015126 \\
\hline & STI & & & & -0.066988 & 0.024242 \\
\hline & Nikkei & & & & 0.005055 & -0.02801 \\
\hline \multirow[t]{2}{*}{ AIC } & KLSE & 11,91271 & 12.19311 & 7.346922 & 11,9329 & 12,20316 \\
\hline & SSEC & 14.20183 & 14.20205 & 10,05848 & 14,23067 & 14.23605 \\
\hline
\end{tabular}




\begin{tabular}{lccccc}
\hline & \multirow{2}{*}{ ARCH (1) } & $\begin{array}{c}\text { GARCH } \\
\mathbf{( 1 , 1 )}\end{array}$ & $\begin{array}{c}\text { GARCH-M } \\
(\mathbf{1 , 1})\end{array}$ & $\begin{array}{c}\text { EGARCH } \\
\mathbf{( 1 , 1 )}\end{array}$ & $\begin{array}{c}\text { TGARCH } \\
(\mathbf{1 , 1})\end{array}$ \\
\hline JKSE & 15.90238 & 15,89737 & 10,48717 & 16,01546 & 15.89822 \\
STI & 12.90465 & 12.90534 & 9.300857 & 12.9594 & 12.90618 \\
Nikkei & 19.16508 & 19.58358 & 13,34266 & 19,17046 & 19.16174 \\
\hline \multicolumn{7}{c}{ Source: Processed with the Eviews10 application }
\end{tabular}

\section{Discussion}

This study involved 5 developing and developed Asian countries with data obtained from 2009 after the 2007-2008 crisis to 2019. The ARCH results showed a significant market fluctuation and volatility in the post-crisis period. Also, the existence of a significant GARCH effect indicated that the past market shock period would be repeated subsequently. This means that the level of volatility when experiencing a shock can be used to describe investors' future returns. According to the GARCH-M model, there were no insignificant risk premiums in all sample countries except in Singapore.

There were no negative shocks found by investors in the asymmetrical model. E-GARCH and T-GARCH modeling results were insignificant in all 5 countries, showing that post-crisis shocks do not largely affect volatility in the capital market. Indonesia also experienced fluctuations in economic growth but did not affect the stock market volatility. This is shown by the absence of asymmetric effects in the sample.

\section{Conclusions and Suggestions}

This study models volatility in developed and developing Asian countries using market indexes. The results showed a non-normality distribution with high kurtosis, stationarity and heteroscedasticity in the five sample countries.

According to Akhtar and Khan [2], significant ARCH effects explain institutional investors' behavior in trade because they affect stock prices in large quantities. Trading in large numbers has a significant impact on share price movements. Moreover, the ASIA stock market's level of volatility describes future returns to investors through stock predictions. Also, the presence of insignificant risk premiums in the four sample countries showed that investors could not get above-average returns by taking higher risks.

The asymmetric parameter was insignificant in all five sample countries, which shows that the market does not necessarily respond to shock and crisis news. Therefore, the global economic crisis that occurred, causing Asian economic growth fluctuation did not affect volatility levels.

Future research can should be conducted, starting from pre to post-crisis to describe the risk and negative shocks more clearly. Furthermore, future research can consider various sectors, such as financial and non-financial entities that influence a country's volatility. More diverse or multivariate models can be used to assess the effects and factors that influence volatility levels.

\section{References}

[1] T. N. Vidanage, F. Carmignani, and T. Singh, "Predictability of Return Volatility Across Different Emerging Capital Markets: Evidence from Asia," South Asian Journal of 
Macroeconomics and Public Finance, vol. 6, no. 2, pp. 157-177, 2017.

[2] S. Akhtar and N. U. Khan, "Modeling volatility on the Karachi stock exchange, Pakistan," Journal of Asia Business Studies, 2016.

[3] P. Sharma, "Forecasting stock market volatility using Realized GARCH model: International evidence," The Quarterly Review of Economics and Finance, vol. 59, pp. 222-230, 2016.

[4] S. Çelik and H. Ergin, "Volatility forecasting using high frequency data: Evidence from stock markets," Economic modelling, vol. 36, pp. 176-190, 2014.

[5] C. M. Lim and S. K. Sek, "Comparing the performances of GARCH-type models in capturing the stock market volatility in Malaysia," Procedia Economics and Finance, vol. 5, pp. 478-487, 2013.

[6] M. Balnaves and P. Caputi, Introduction to quantitative research methods: An investigative approach. Sage, 2001.

[7] K. E. Howell, An introduction to the philosophy of methodology. Sage, 2012.

[8] M. Ariefianto, "Ekonometrika: Esensi dan Aplikasi (Econometrics: An Essence and Application Using Eviews)," Jakarta: Erlangga, 2012.

[9] D. A. Dickey and W. A. Fuller, "Distribution of the estimators for autoregressive time series with a unit root," Journal of the American statistical association, vol. 74, no. 366a, pp. 427-431, 1979.

[10] D. A. Kuhe, M. A. Chiawa, S. C. Nwaosu, and J. A. Ikughur, "Modeling Volatility of Asset and Volume of Trade Returns in the Nigerian Stock Market in the Presence of Random Level Shifts," Asian Journal of Probability and Statistics, pp. 1-25, 2019.

[11] S. Z. S. Abdalla and Z. Suliman, "Modelling stock returns volatility: Empirical evidence from Saudi Stock Exchange," International Research Journal of Finance and Economics, vol. 85, pp. 166-179, 2012.

[12] H. C. Huang, Y.-C. Su, and J.-T. Tsui, "Asymmetric GARCH Value-at-Risk over MSCI in Financial Crisis," International Journal of Economics and Financial Issues, vol. 5, no. $2,2015$.

[13] A. SHAMIRI, Z. ISA, and A. FREEDI, "A STUDY OF THE BEHAVIOR OF VOLATILITY IN SAUDI ARABIA STOCK MARKET," No. Paper ID, p. 788, 2010. 